\title{
A POSIÇÃO-SUJEITO \\ GRAMÁTICO: UMA DAS \\ POSIÇÕES ASSUMIDAS POR \\ ANDRÉS BELLO ${ }^{1}$
}

\section{LA POSICIÓN SUJETO GRAMÁTICO: UNA DE LAS POSICIONES ASUMIDAS POR ANDRÉS BELLO}

\author{
THE GRAMMATICAL SUBJECT-POSITION: ONE OF THE POSITIONS HELD \\ BY ANDRÉS BELLO
}

Kelly Cristini Granzotto Werner*

Universidade Federal de Santa Maria

RESUMO: Sob a perspectiva teórica da História das Ideias Linguísticas na sua relação com a Análise do Discurso (AD) e a Enunciação, este artigo tem por objetivo propor uma reflexão sobre a posição-sujeito gramático assumida por Andrés Bello na Gramática de la lengua castellana destinada al uso de los americanos (1847, Chile) e mostrar que não é a única que se revela nesse discurso. Além disso, lançamos um olhar sobre os lugares sociais ocupados e a voz assumida pelo autor no seu percurso de vida, que também podem dar a conhecer outras posições-sujeito. Suas diferentes ocupações levam-no à produção de saber científico e intelectual. A partir da análise de alguns enunciados do prefácio da obra, buscamos compreender o que as posições-sujeito revelam. Os resultados obtidos indicam a dispersão do sujeito no material analisado.

PALAVRAS-CHAVE: História das Ideias Linguísticas. Posição-sujeito. Gramática. Andrés Bello.

RESUMEN: Bajo la perspectiva teórica de la Historia de las Ideas Lingüísticas en su relación con el Análisis del Discurso y la Enunciación, este artículo tiene por objetivo proponer una reflexión sobre la posición sujeto gramático asumida por Andrés Bello en la Gramática de la lengua castellana destinada al uso de los americanos (1847, Chile) y mostrar que nos es la única que se presenta

\footnotetext{
Trabalho apresentado à disciplina "Sujeito e discurso - módulo I", do Programa de Pós-Graduação em Letras da Universidade Federal de Santa Maria (UFSM), durante o lo semestre de 2018 , ministrada pela Profa. Dra. Verli Petri, a quem agradeço a primeira leitura e as sugestóes.

* Professora do Colégio Politécnico da Universidade Federal de Santa Maria e Doutoranda em Letras - Estudos Linguísticos pela Universidade Federal de Santa Maria (UFSM), sob a orientação da Profa. Dra. Eliana Rosa Sturza. Email:kcgbr@yahoo.com.br.
} 
en ese discurso. Además, lanzamos una mirada sobre los lugares sociales ocupados y sobre la voz asumida por el autor en su trayectoria de vida, que también pueden dar a conocer otras posiciones sujeto. Sus distintas ocupaciones le llevan a la producción de saber científico e intelectual. A partir del análisis de algunos enunciados del prólogo de la obra, buscamos comprender qué las posiciones sujeto revelan. Los resultados obtenidos indican la dispersión del sujeto en el material analizado.

PALABRAS CLAVE: Historia de las Ideas Lingüísticas. Posición sujeto. Gramática. Andrés Bello.

ABSTRACT: Under the theoretical perspective of History of Linguistic Ideas in its relation with Discourse Analysis (DA) and Enunciation, this article's objective is to propose a reflection on the grammarian subject-position held by Andrés Bello in Gramática de la lengua castellana destinada al uso de los americanos (1847, Chile) and to show that it is not the only one that reveals itself in this discourse. Furthermore, we take a critical look on the occupied social places, which may also know other subject-positions, and the voice taken by the author in his life journey. His different occupations lead him to scientific and intellectual knowledge production. From the analysis of some statements in the book's preface, we aim at comprehending what the subject-positions reveal. The results indicate the dispersion of the subject in the analysed material.

KEYWORDS: History of Linguistic Ideas. Subject-position. Grammar. Andrés Bello.

\section{CONSIDERAÇÕES INICIAIS}

A produção gramatical de Andrés Bello não se resume, como se sabe, à Gramática de la lengua castellana destinada al uso de los americanos (1847), embora seja sua obra de maior destaque. Há quatro versões posteriores da obra, revisadas por Bello (1850, 1853, 1857 e 1860), e outras duas mais que surgiram no Chile, ainda em vida do autor, em 1862 e 1864, e nestas não fez mudanças. Tomamos a primeira edição, disponível online, na Biblioteca Nacional Digital do Chile.

Como se configura a gramática em estudo? Apresenta um Prólogo de nove páginas, dividido em doze números, uma página de Erratas, uma página de Noções Preliminares, cinquenta e um capítulos² e dezenove páginas de notas de fim.

Sob a perspectiva teórica da História das Ideias Linguísticas (HIL) na sua relação com a Análise do Discurso (AD) e a Enunciação, buscamos investigar, neste artigo, o funcionamento da posição-sujeito gramático na obra citada. Para tal, observamos enunciados do Prólogo. Faz-se também necessário revisitar na teoria, a noção de sujeito. Mas antes é preciso entender quem é Andrés Bello? Que sujeito é esse? Que posições-sujeito assume a partir das atividades que desenvolve?

\section{UM OLHAR SOBRE O SUJEITO ANDRÉS BELLO}

Antes de analisar o discurso de Andrés Bello, entendemos necessária uma incursão na sua vida, porque as condições de produção interferem nas posições que o sujeito vem a ocupar, bem como no saber que vem a produzir. Há diferentes momentos na trajetória de Bello: a formação intelectual na Venezuela, seu país natal, e algumas produções (1781-1810), os estudos e a diplomacia em Londres (1810-1829), o regresso à América Latina e a vida no Chile (1829-1865), sendo esta última, a mais fecunda da produção e atuação do autor.

Don Andrés Bello nasceu em Caracas, Venezuela, em 1781, e faleceu no Chile, em 1865, com 84 anos. Pertenceu a uma família estudada (seu pai era advogado e sua mãe era de uma família de artistas), e teve acesso à educação clássica e religiosa. Sabia Latim, francês e inglês e era leitor e estudioso de textos europeus. Foi, inclusive, professor de Simon Bolívar nos tempos de Caracas. Atuou como diplomata em Londres durante 19 anos. No seu regresso, à América (Chile), em 1829, trabalhou no jornalismo, ministrou aulas, foi o primeiro reitor da Universidade do Chile (1843), ocupou cargos políticos e públicos, redigiu o Código Civil de la República de Chile (1856), publicou a Gramática dela lengua castellana destinada al uso de los americanos (1847) e outras obras

\footnotetext{
${ }^{2}$ Em edições mais recentes da gramática (por exemplo, a de 1984), os editores subdividiram os capítulos em números. Na versão citada, há 1288 números. Também apresenta Prefácio e um Apêndice. Há edições que consideram 50 capítulos. Há também as que apresentam índice.
} 
importantes sobre língua. Viveu, portanto, os últimos ares do século XVIII e parte do XIX, períodos marcados pelos movimentos pró-independência das colônias hispano-americanas e estruturação das jovens nações.

A produção linguística reúne um conjunto de artigos publicados em jornais da época, entre eles, Gramática castellana (1832), Análisis ideológica de los tiempos verbales (1841), tratado de ortografia e obras como a Gramática dela lengua castellana destinada al uso de los americanos (1847), Compendio de gramática castellana para el uso de las escuelas primarias (1851), Obras Completas (1955). Na verdade, suas obras nascem de um processo de escrita e de pensamento que vem sendo gestado e desenvolvido desde os anos de Londres.

Em 1851, foi designado membro da Real Academia Española. Sua vida foi recheada de trabalhos variados, escrevendo e publicando textos nos campos linguístico, filosófico, literário, jurídico e histórico. Foi reconhecidamente um polígrafo e uma figura representativa para a civilização hispano-americana, que buscava a liberdade em relação à metrópole. Além disso, foi um patriota $\mathrm{e}$ viveu o sonho de Bolívar de uma América unificada (BARROS, 2003, p. 43). É visto como uma personalidade importante da história chilena, mas também uma figura transnacional.

\section{A NOÇÃO DE SUJEITO}

Para observar o sujeito na obra, faz-se necessário recuperar, na teoria, a noção de sujeito. Tomamos aqui perspectivas teóricas diferentes, a teoria da enunciação de Émile Benveniste e a AD de Michel Pêcheux. Essa retomada, tão necessária para as respostas das nossas questões iniciais, caminha no sentido proposto por Auroux (2014), quando fala em horizontes de retrospecção e projeção. Precisa-se valorizar os saberes do passado, para compreender o presente e para, quem sabe, promover um futuro.

\subsection{A NOÇÃO DE SUJEITO NOS ESTUDOS ENUNCIATIVOS DE BENVENISTE}

A partir dos estudos e vastos trabalhos analíticos de Benveniste, reunidos nos conhecidos Problemas de Linguística Geral I e II, publicados em dois volumes, sendo o primeiro em 1966 e o segundo em 1977, podemos falar de uma teoria da enunciação. Seu pensamento possibilitou, em caráter inovador, a reintegração do sujeito nos estudos da linguagem, categoria excluída pelo corte saussuriano. Essa reinserção também permitiu um avanço em direção aos estudos do discurso. Percebe-se que Benveniste devolve ao sujeito seu lugar, a partir do momento em que concebe a linguagem de modo diferente do que se vinha pensando na época. Isso significa admitir a (inter)subjetividade como algo que lhe é constitutivo. Ou dizendo de outro modo, requer acolher a dimensão subjetiva da linguagem. Sendo assim, o sujeito passa de elemento excluído a elemento essencial. Essa ideia está no artigo "Da subjetividade na linguagem" (1958): "É na linguagem e pela linguagem que o homem se constitui como sujeito; porque só a linguagem fundamenta na realidade, na sua realidade que é a do ser, o conceito de ego." (BENVENISTE, 1958, p. 286).

A partir dessa colocação, Petri (2004) afirma que o sujeito benvenistiano é um "sujeito egocêntrico", que dono do seu dizer, na medida em que ego é sinônimo de eu. Ou seja, é o pronome eu. Para Benveniste, a definição de subjetividade é a capacidade do locutor se propor como sujeito, ou seja, assumir a palavra e dizer ego (=eu). Neste mesmo artigo, também está dito:

\footnotetext{
Não atingimos nunca o homem separado da linguagem e não o vemos nunca inventando-a. Não atingimos o homem reduzido a si mesmo e procurando conceber a existência do outro. É um homem falando que encontramos no mundo, um homem falando com outro homem, e a linguagem ensina a própria definição de homem. (BENVENISTE, 1958, p. 285).
}

Ou seja, o homem é um ser de linguagem. Mas não o é sozinho, precisa do outro. O eu é o locutor; este se enuncia como sujeito e implanta diante de si um tu, o alocutário, que pode, pela propriedade da reversibilidade, ser um eu. É a linguagem que viabiliza a existência de eu - tu, enquanto sujeitos, mediante o respeito à condição de diálogo. Ou seja, entendemos que a subjetividade, pensada por Benveniste (1958), não é projetada no eu, mas sim na relação de intersubjetividade do par eu-tu, acontecida em um aqui-agora. 
Desse modo, esse vínculo dos sujeitos é dialógico por natureza. Para o autor (1958, p. 287), "é numa realidade dialética que englobe os dois termos e os defina pela relação mútua que se descobre o fundamento linguístico da subjetividade”.

Esse fundamento, que é linguístico, repousa representativamente na noção de pessoalidade e se dá por contraste. A categoria de pessoa existe em qualquer língua e, por isso, a possibilidade da subjetividade na linguagem também. Benveniste reconhece como pessoa, eu e tu, e como não pessoa, o ele. Nela se ancoram as demais parceiras que demonstram o sujeito, a espacialidade e a temporalidade, ou seja, categorias de espaço e tempo, formando a tríade eu/tu-aqui-agora.

Isso quer dizer que, para Benveniste (1956), a subjetividade pode ser identificada materialmente em um enunciado através de algumas formas que a língua empresta ao locutor - a dêixis (as funções sintáticas também ${ }^{3}$ ). Em o fazendo, transforma-se em sujeito. Tais marcas seriam pronomes pessoais, verbos e advérbios. Assim, a língua comporta índices especiais, em seu interior, os reveladores da subjetividade, que se encontram à disposição de todo locutor que os deseje assumir e falar.

É evidente que a existência da subjetividade se dá na e pela linguagem, mas é a atitude do locutor diante da língua que ativa essa propriedade e assim deve ser porque não haveria possibilidade de dispor, para cada indivíduo, signos específicos para marcar a sua subjetividade. Todos usam os mesmos. Depois da enunciação, estão livres e vazios, de sentido e referência, novamente, para outro locutor. De acordo com Benveniste (1958, p. 288), "a linguagem está de tal forma organizada que permite a cada locutor apropriarse da língua toda designando-se como eu." Para o autor (1958), não há outra forma de o indivíduo legitimar sua subjetividade senão pelo testemunho dado por ele mesmo para um outro. Então, o sujeito se apropria da língua e também a atualiza.

Desse modo, para entender como o sujeito se constitui e faz sentido em um estudo que tem por base a teoria da enunciação de Benveniste, podemos partir da observação e análise das categorias de pessoa, de tempo (1965) e de espaço, sendo que a primeira é o parâmetro para as demais. Isto é, quando fazemos um estudo enunciativo, buscam-se as marcas do sujeito na enunciação.

Enquanto locutor, podemos pensá-lo como fonte da enunciação, mas o sentido de sua mensagem, a natureza do dizer é heterogênea, porque necessita do outro (alocutário) para enunciar. Pode ser que haja uma ilusão de ser o centro do dizer e do sentido, mas isso é necessário à enunciação.

A partir dessas ideias sobre o sujeito, a linguagem e o sentido, pode-se observar em Benveniste uma teoria subjetiva da linguagem. Passemos agora a ver como a AD fez o resgate do sujeito e como o entende. Pêcheux retoma essa categoria, a partir de Benveniste, linguista que a traz para a Ciência Linguística e a reformula.

\subsection{A NOÇÃO DE SUJEITO NOS ESTUDOS DISCURSIVOS DA AD PECHEUXIANA}

Embora também comungue da ideia de Benveniste de que o sujeito se constitui na e pela linguagem, a AD, proposta por Pêcheux, questiona o subjetivismo idealista, isto é, o sujeito origem da enunciação, homogêneo porque acredita que é afetado por elementos exteriores: a ideologia, o inconsciente e a história. Isso se justifica se observarmos a própria constituição da $\mathrm{AD}$, como uma "disciplina de entremeio" (ORLANDI, 2003), no sentido de que tem por base epistemológica a Linguística, a Psicanálise e o Marxismo. Pêcheux (2014), portanto, pensa em uma teoria não-subjetiva da subjetividade.

Desse ponto de vista discursivo, o sujeito é afetado por dois esquecimentos, $\mathrm{n}^{\circ} 1$ e $\mathrm{n}^{\circ} 2$. O esquecimento $\mathrm{n}^{\circ} 1$ é de natureza ideológica - inconsciente, em que o sujeito tem a ilusão de ser a fonte do dizer, quando, na verdade, retoma já ditos, a partir da ação da ideologia e do inconsciente sobre ele. Nesse sentido, pensa ser o criador do seu discurso. Pêcheux (2014, p. 144) traz a metáfora do "efeito Münchhausen" para ilustrar essa ideia de que o indivíduo é interpelado em sujeito pela ideologia. Tem-se, portanto, a ilusão subjetiva a partir do assujeitamento ideológico. O esquecimento no 2 é de caráter pré-consciente e, neste, o sujeito pensa que o que

\footnotetext{
${ }^{3}$ Em O Aparelho formal da enunciação (1970), Benveniste sintetiza a teoria da enunciação, mostrando o que seria, de fato, esse aparelho formal. Apreende-se que é um conjunto de elementos da língua - os índices de pessoa, espaço e tempo (dêixis) e as funções sintáticas (interrogação, intimação e asserção); concluindo que a enunciação está na língua inteira. O locutor pode se apropriar do aparelho formal da língua e atualizá-lo.
} 
diz tem apenas um significado ou ainda que só pode ser dito daquela forma. Este esquecimento produz a ilusão do sentido literal ou do controle do sentido pelo sujeito, o que não é possível. O autor defende que esses esquecimentos são necessários para a produção de novos discursos e sentidos. Tais discursos se caracterizam por processos parafrásticos e polissêmicos, na medida em que o sujeito passaria a reformular, a reiterar o já existente (o mesmo) e a deslocar, produzindo novos sentidos (o diferente). É nesse movimento que o sujeito e o sentido significam. O sujeito, que é histórico e ideológico, pode ser considerado um efeito, uma consequência da linguagem. Apresenta-se assujeitado e em posições-sujeito. Ou seja, há um deslocamento da noção em relação a Benveniste.

O sujeito se constitui por posições-sujeito porque se forma pelas vozes de outros sujeitos. Segundo Pêcheux (2014, p.139) as marcas da ideologia e do inconsciente produzem um "tecido de evidências subjetivas" que entram na constituição do sujeito e que podem ser percebidas no seu discurso. A tomada de posição do sujeito produz desdobramentos entre o sujeito da enunciação e o sujeito universal, e isso pode levá-lo a diferentes modalidades de inscrição, as quais o autor (2014) denominou: identificação, contraidentificação e desidentificação.

A primeira delas se dá quando há superposição do sujeito da enunciação com o sujeito universal, ou seja, o sujeito se identifica plenamente com a formação discursiva $(\mathrm{FD})^{4}$ que o domina, produzindo a ideia de unidade/unicidade. Disso resulta o efeito sujeito. Porém, Pêcheux (2014) mostra que isso é da ordem da ilusão. O autor denominou de "bom sujeito", essa figura que consente essa identificação e por ela se ilude.

A contra-identificação ocorre quando o sujeito do dizer produz um discurso que se contrapõe ao do sujeito universal, ou seja, ele toma uma posição que o afasta em alguma medida do que lhe afeta. A FD de ambos é a mesma, mas não é mais homogênea, porque o sujeito discursivo questiona, duvida, contesta saberes da FD dominante. Portanto, ocorre uma identificação com ressalvas entre os sujeitos. Essa tomada de posição levou Pêcheux (2014) a entender que essa modalidade comporta o discurso do "mau sujeito".

Outra modalidade de funcionamento subjetivo é a desindentificação. Dá-se quando o sujeito da enunciação não se identifica mais com o sujeito universal. Desloca-se a outra FD, com a qual passa a se identificar. Isso não significa que o sujeito conquistou a "sonhada liberdade" total, ainda que possa ali se movimentar, nem que não "carregue" consigo marcas da FD anterior. Parafraseando Indursky (2008), nessa forma de inscrição, a FD é heterogênea (Pêcheux (1983) admitiu a heterogeneidade) e, consequentemente, produz um sujeito heterogêneo, fragmentado ${ }^{5}$.

Percebemos então que a concepção de sujeito da enunciação, de Benveniste, diferencia-se da AD, no sentido de que há um deslocamento do sujeito centro, constituído na/pela linguagem, para um sujeito também constituído via linguagem, mas descentrado, assujeitado, que se apresenta por posições-sujeito, determinado (junto como os sentidos) pela história e pela ideologia (e ainda atravessado pelo inconsciente). Revela-se um sujeito complexo e contraditório.

Nos estudos enunciativos atuais há mudanças. E apenas para citarmos um exemplo disso, Guimarães (2017), nas suas pesquisas, sobre a "Semântica do Acontecimento", considera que a linguagem não é transparente, que tem relação com a história, de modo a defender uma "concepção enunciativa e histórica da linguagem" (2017, p. 8). Logo, as categorias de sujeito e de sentido são analisadas, a partir das condições sócio-históricas. Manifesta-se o semanticista (1998, p. 115): "E assim, como o sentido é também memória discursiva (interdiscurso), a identidade do sujeito não é de sua própria autoria, e nem lhe é completamente acessível.”

\section{AS POSIÇÕES-SUJEITO}

A história de vida de Andrés Bello revela que ele é um homem de dois mundos: o americano (Venezuela e Chile) e o europeu (Inglaterra). Isso pode nos antecipar que essa realidade faça parte da constituição do sujeito, entendida como uma categoria formada

\footnotetext{
${ }^{4}$ Pêcheux (2014, p. 147) chama de FD “[...] aquilo que, numa formação ideológica dada, isto é, a partir de uma posição dada numa conjuntura dada, determinada pelo estado da luta de classes, determina o que pode e deve ser dito[...]”. Para essa vertente teórica, o sujeito discursivo se inscreve prioritariamente em uma FD.

${ }^{5}$ Indursky (2008) desenvolve a questão dos desdobramentos do sujeito no discurso porque acredita que pode se dividir em mais posições do que aquelas apontadas por Pêcheux (1975). Nesse sentido, apresenta como possibilidade a "fragmentação da forma-sujeito".
} 
de outras vozes. Além disso, ao analisar uma gramática, no caso, a Gramática de la lengua castellana destinada al uso de los americanos (1847), também é natural projetar que a posição-sujeito gramático possa perpassar prioritariamente na obra e, coladas a ela, surgem a imagem daquele que sabe a língua e sobre a língua, a autoridade, e a lembrança das condições sócio-históricas de produção desse instrumento, já apontadas neste trabalho. Ou seja, essa gramática foi produzida e publicada em um período referente ao processo de independência das colônias hispano-americanas e sua consolidação como nações. Orlandi (2002, p. 206) nos ensina que, na produção de instrumentos linguísticos, ocorre "o funcionamento de duas discursividades: a do gramático e a do linguista, este às vezes desejado, outras vezes detestado”. Passemos da antecipação e do imaginário à observação, de fato, de como o sujeito se constitui e se movimenta na gramática em estudo, tomando seu Prefácio.

Este texto é um elemento que antecede o texto principal e tem por função apresentar, explicar, representar, divulgar a obra que lhe sucede. Pode ser escrito e assinado pelo próprio autor ou não. No caso específico, Bello escreve o prefácio, mas não o assina. É um discurso sobre a língua, que é costurado pelo gramático, uma vez que é constituído de outras vozes para um público específico, convencionalmente acordado, que são os que consultam a obra. No caso de Bello, no prefácio, seus interlocutores são especialistas, leitores inteligentes, professores, alunos, ou seja, destinatários caracterizados de forma diferente do destinatário do título da gramática, que é mais geral, não é nem nacional, mas continental - os americanos. Consideradas essas características, podemos encontrar as marcas da subjetividade daquele que produz a obra. Para este trabalho, vamos buscar os elementos linguísticos que nos revelam a presença das posições-sujeito no discurso selecionado.

A partir de um gesto de leitura atenta do Prefácio (Prólogo, no caso), identificamos as posições-sujeito: posição-sujeito falante de castelhano, posição-sujeito gramático, posição-sujeito professor/educador e posição-sujeito estudioso da língua/cientista (linguista). Constrói-se, na sequência, um gesto de interpretação possível entre outros sobre o tema ${ }^{6}$.

a) Posição-sujeito falante da língua

Antes de mais nada, Bello é um homem falando no mundo, como disse Benveniste (1958), no mundo hispano-americano para outros hispano-americanos. Então, é um sujeito falante do castelhano. Estabelece, portanto, uma primeira relação com a língua que é a de falante. Nesse sentido, o princípio da subjetividade se constitui na relação intersubjetiva com seus compatriotas ${ }^{7}$.

Si segun la practica jeneral de los americanos es mas analójica la conjugacion de algun verbo, ¿por qué razon hemos de preferir la que caprichosamente haya prevalecido en Castilla? Si de raices castellanas hemos ${ }^{8}$ formado vocablos nuevos, segun los procederes ordinarios de derivación, que el castellano reconoce, i de que se ha servido i se sirve contínuamente para aumentar su caudal de voces, ¿qué motivo hai para que nos avergoncemos de usarlos? Chile i Venezuela tienen tanto derecho como Aragon i Andalucia para que se toleren sus accidentales diverjencias, cuando las patrocina la costumbre uniforme i auténtica de la gente educada. ${ }^{9}$

\section{Recorte 1}

Fonte: Bello (1847, XII)

\footnotetext{
${ }^{6}$ Sobre o tema, Surdi (2017) faz um extenso estudo em gramáticas de Rocha Lima, no Brasil.

${ }^{7}$ O Prólogo da Gramática de Bello é praticamente um diálogo, revelando, explicitamente na superfície linguística, o(s) interlocutor(es). O texto é construído na relação intersubjetiva e imaginada pelo autor. Isso ratifica a tese benvenistiana tão bem aceita de que, no mundo, há um homem falando para outro homem. (BENVENISTE, 1958)

${ }^{8}$ Os negritos são nossos nos recortes

${ }^{9}$ Se segundo a prática geral dos americanos é mais analógica a conjugação de algum verbo, por que razão temos de preferir a que caprichosamente tenha prevalecido em Castela? Se de raízes castelhanas formamos vocábulos novos, segundo os procedimentos originários de derivação, que o castelhano reconhece, e de que se serviu continuamente para aumentar o seu repertório de vozes, que motivo existe para que nos envergonhemos de usá-los? Chile e Venezuela possuem tanto direito quanto Aragão e Andaluzia para que se tolerem suas divergências acidentais, quando as patrocina o costume uniforme e autêntico da gente educada. (tradução nossa)
} 
Destacamos, no recorte, as formas verbais e pronominais "hemos", "hemos formado", "nos avergoncemos" como marcas linguísticas da subjetividade, que revelam a posição de sujeito falante do castelhano. Escolhe o "nós inclusivo", elíptico nos verbos e explícito no pronome "nos", para incluir-se e identificar-se com os americanos. Ao tomar essa posição, o sujeito-gramático desliza e passa a ser mais um na comunidade de falantes daquela língua. Essa posição-sujeito se descortina em algum outro momento do Prólogo, silenciando-se na maior parte. Nesse aspecto, poderíamos pensar em identificação plena.

Ainda é preciso observar, no recorte 1, a seguinte sequência enunciativa "cuando las patrocina la costumbre uniforme i auténtica de la gente educada". Aqui poderíamos cogitar duas situações: no retorno da posição-sujeito gramático, normatizador, quando parece ditar uma regra para o direito linguístico ser garantido, a condição de que seja um uso da "gente educada", isto é, daqueles que têm a cultura da tradição letrada ocidental; ou ainda, na confirmação da posição-sujeito falante educado/culto, considerando sua formação intelectual, que mostra a identificação com "la gente educada". Isso nos leva a pensar que não há uma identificação plena entre Bello e os falantes americanos do castelhano. Tampouco se identifica plenamente com a posição-sujeito gramático da FD que o domina, porque inova ao promover o uso como a norma da língua. Esse "uso" comporta os modelos da literatura castelhana, o uso culto do dialeto de Castela e o uso da gente educada da América (ainda que este seja menos expressivo no texto). Então, nesse recorte, o sujeito se mostra contraditório, pois se movimenta entre a identificação e a contra-identificação.

A análise desse fragmento também nos afasta da ideia de sujeito homogêneo, pensada por Benveniste e nos aproxima da ideia de sujeito dividido em posições-sujeito, defendida por Pêcheux. Nesse caso, apresenta-se um sujeito que se inscreve em uma FD dominante, com a qual, às vezes, se identifica, e, em outras, se contra-identifica.

b) Posição-sujeito gramático

A posição-sujeito gramático também pode ser identificada nos recortes 2, 3 e 4 e em outras partes do extenso prefácio, o que vai nos revelar que essa é a posição-sujeito predominante, inscrita em uma FD dominante em relação aos interlocutores. Também é preciso considerar que ela interfere nas demais posições, uma vez que ele é responsável por organizar, selecionar os saberes no livro gramática. É dessa posição-sujeito que pode assumir a função de autoria da obra. Evidentemente que seu fazer atende as condições sócio-históricas. No caso de Bello, atende a um projeto de representação da unidade da língua, da identidade (trans)nacional, perante o Estado. Funciona como um instrumento pedagógico, que prescreve o uso da língua da gente educada.

No recorte 2, a preocupação com a preservação da unidade da língua (pura) é revelada na palavra “conservação", que está adjetivada por "importante".

No tengo la presuncion de escribir para los castellanos. Mis lecciones se dirijen a mis hermanos, los habitantes de Hispano-América. Juzgo importante la conservacion de la lengua de nuestros padres en su posible pureza, como un medio providencial de comunicacion i un vínculo de fraternidad entre las varias naciones de orijen español derramadas sobre los dos continentes. Pero no es un purismo supersticioso lo que me atrevo a recomendarles. ${ }^{10}$

\section{Recorte 2}

Fonte: Bello (1847, X-XI)

A posição do sujeito-gramático é encabeçada por "juzgo" e finalizada com "recomendarles”, ambos verbos de ação. Tais ações são tomadas por alguém que é autoridade linguística. Observemos, na sequência, o recorte 3.

\footnotetext{
${ }^{10}$ Não tenho a presunção de escrever para os castelhanos. Minhas lições se dirigem aos meus irmãos, os habitantes de hispano-américa. Julgo importante a conservação da língua de nossos país em sua possível pureza, como um meio providencial de comunicação e um vínculo de fraternidade entre as várias nações de origem espanhola derramadas sobre os dois continentes. (tradução nossa).
} 
Tal ha sido mi lójica. En cuanto a los auxilios de que he procurado aprovecharme, debo citar especialmente las obras de la Academia española i la gramática de D. Vicente Salva. He mirado esta última como el depósito mas copioso de los modos de decir castellanos; como un libro, que ninguno de los que aspiran a hablar i escribir correctamente nuestra lengua nativa debe dispensarse de leer i consultar amenudo. Soi tambien deudor de algunas ideas al injenioso i docto D. Juan Antonio Puigblanch en las materias filolójicas que toca por incidencia en sus Opúsculos. Ni fuera justo olvidar a Garcés, cuyo libro, aunque solo se considere como un glosario de voces i frases castellanas de los mejores tiempos, ilustradas con oportunos ejemplos, no creo que merezca el desden con que hoi se le trata. ${ }^{11}$

\section{Recorte 3}

Fonte: Bello (1847, VIII-IX)

Nesse recorte, Bello revela suas fontes para escrever a gramática. Faz menção a quatro referências, mostrando respeito aos clássicos e defendendo os modos exemplares de se dizer em castelhano, que, na história das gramáticas, advêm da literatura. Na história da gramatização de uma língua, era comum o autor apoiar-se na autoridade literária, tomando fragmentos de textos literários para descrever e recomendar a língua. Bello, na posição de sujeito-gramático também faz isso e confessa quando usa expressões como "aprovecharme", "depósito", "deudor", "glosario de voces”, e outras visíveis no recorte. Portanto, vale-se de exemplos da literatura para legitimar as regras prescritas.

A posição-sujeito gramático também se marca fortemente no recorte 4. Destacamos alguns elementos do funcionamento normatizador nesta enunciação:

Hai en la gramática muchos puntos que no son accesibles a la intelijencia de la primera edad; i por eso he juzgado conveniente dividirla en dos cursos, reducido el primero a las nociones ménos difíciles i mas indispensables, i extensivo el segundo a aquellas partes del idioma que piden un entendimiento algo ejercitado. Los he señalado con diverso tipo $i$ comprendido los dos en un solo tratado, no solo para evitar repeticiones, sino para proporcionar a los profesores del primer curso el auxilio de las explicaciones destinadas al segundo, si alguna vez las necesitaren. [...] En las notas al pié de las páginas menciono los arcaismos, llamo la atencion a ciertas prácticas viciosas del habla popular de los americanos para que se conozcan i eviten; i dilucido algunas doctrinas con observaciones que requieren el conocimiento de otras lenguas. ${ }^{12}$

\section{Recorte 4}

Fonte: Bello (1847, X)

Revela-se a ação daquele que detém o saber sobre a língua e prescreve normas para o seu bom uso. A força normatizadora dessa posição-sujeito se mostra ao dividir a obra em dois cursos, ao apontar distintos destinatários e ao fazer o corte entre a língua da

\footnotetext{
${ }^{11}$ Tal foi minha lógica. Em relação aos auxílios de que procurei aproveitar-me, devo citar especialmente as obras da Academia espanhola e a gramática de D, Vicente Salvá. Olhei esta última como o depósito mais abundante dos modos de dizer castelhanos; como um livro, que nenhum dos que aspiram a falar e a escrever corretamente nossa língua nativa deve dispensar-se de ler e consultar frequentemente. Sou também devedor de algumas ideias ao engenhoso e douto D. Juan Antonio Puigblanch nas matérias filosóficas que toca por incidência em seus Opúsculos. Nem fora justo esquecer a Garcés, cujo livro, embora se considere como um glossário de vozes e frases castelhanas dos melhores tempos, ilustradas com exemplos oportunos, não acredito que mereça o desdém com hoje se trata. (tradução nossa).

${ }^{12}$ Há na gramática muitos pontos que não são acessíveis à inteligência da primeira idade; e, por isso, julguei conveniente dividi-la em dois cursos, reduzido o primeiro as noções menos difíceis e mais indispensáveis, e extensivo o segundo àquelas partes do idioma que exigem um entendimento mais exercitado. Marquei-os com tipo diferente e compreendido os dois em um só tratado, não somente para evitar repetições, mas sim para proporcionar aos professores do primeiro curso o auxílio das explicações destinadas ao segundo, se alguma vez as necessitarem. [...] Nas notas de rodapé, menciono os arcaísmos, chamo a atenção para certas práticas viciosas da fala popular dos americanos para que se conheçam bem e evitem; e elucido algumas doutrinas com observações que requerem o conhecimento de outras línguas (tradução nossa).
} 
"gente educada" (norma), disposta no corpo da gramática, e as demais modalidades de língua (a diversidade de usos americanos), apresentadas em notas de rodapé.

c) Posição-sujeito professor/educador

A posição-sujeito gramático desloca-se em um determinado momento para a posição sujeito professor. No recorte 5 há uma mostra disso.

No tengo la presuncion de escribir para los castellanos. Mis lecciones se dirijen a mis hermanos, los habitantes de Hispano-América. ${ }^{13}$

\section{Recorte 5}

Fonte: Bello (1847, X)

Apontamos o grupo nominal "mis lecciones". Na língua espanhola, a palavra "lección”, segundo o dicionário da RAE, tem oito acepções. Chamo a atenção para duas delas. Uma, pode ser tudo o que o professor ensina ao seu discípulo, as instruções, o conjunto de ensinamentos. Nesse sentido, a escolha do autor sinaliza outra tomada de posição, além da de gramático, que é a de professor. Ele se inscreve nessa posição-sujeito dominante, em relação aos seus alunos - os seus irmãos hispano-americanos. Se relembrarmos a sua história de vida, não é de se estranhar o aparecimento da atividade de educador que sempre desenvolveu. Essa tomada de posição é que faz dele o sujeito que se contra-identifica com os saberes de uma FD da norma culta, pois ele se preocupa em ensinar, em fazer o diferente acontecer.

A outra acepção de "lección" se refere a cada um dos capítulos ou partes de um escrito, no caso, da gramática. Considerando esse sentido, temos a palavra como uma marca da posição-sujeito gramático, que se identifica novamente como dominante.

Nesse recorte, portanto, apresenta-se o sujeito dividido, marcado pela contradição.

d) Posição-sujeito estudioso da língua/cientista (linguista)

Nos recortes 6 e 7, percebemos mais uma tomada de posição do sujeito da produção de conhecimento que se aloca na posiçãosujeito estudioso da língua, um cientista (linguista, talvez, na época, filólogo)

El habla de un pueblo es un sistema artificial de signos, que bajo muchos respectos se diferencia de los otros sistemas de la misma especie; de que se sigue que cada lengua tiene su teoría particular, su gramática. ${ }^{14}$

\section{Recorte 6}

Fonte: Bello (1847, VI)

\footnotetext{
${ }^{13}$ Não tenho a presunção de escrever para os castelhanos. Minhas lições se dirigem aos meus irmãos, os habitantes de hispano-américa. (tradução nossa)

${ }^{14}$ A fala de um povo é um sistema artificial de signos, que sob muitos aspectos se diferencia de outros sistemas da mesma espécie; de que se segue que cada língua tem/possui sua teoria particular, sua gramática (tradução nossa).
} 
Una lengua es como un cuerpo viviente: su vitalidad no consiste en la constante identidad de elementos, sino en la regular uniformidad de las funciones que estos ejercen, i de que proceden la forma i la indole que distinguen al todo. ${ }^{15}$

\section{Recorte 7}

Fonte: Bello (1847, IX-X)

No recorte 6, podemos observar duas incidências da palavra "sistema", atrelada à visão de língua. A concepção bellista de língua é declarada em "El habla de un pueblo es un sistema artificial de signos". Ao dizer isso, defende o caráter sistêmico e cultural da língua, ela não é um produto natural. É uma construção social. Esse modo de pensar nos projeta ao futuro, especificamente, a Saussure, autor do CLG (1916), que também proclamou a língua como um conjunto/um sistema de convenções e um produto social.

No recorte 7, especialmente em "Una lengua es como un cuerpo viviente", há a compreensão de que a língua evolui através do tempo e do espaço. Por se mostrar um produto cultural dinâmico, ela está sempre se recriando. Saussure (1916) apresentará essa ideia sessenta e nove anos mais tarde.

Revela-se, pelas duas ideias, trazidas nos recortes 6 e 7 , mais que uma atitude de gramático, mas a atitude científica, mostrada na sua definição e entendimento de língua, que aproximam-no de uma determinada corrente linguística que ainda não havia nascido, que ainda não tinha status de ciência, a Linguística Moderna de Saussure. Logo, esse sujeito que se inscreve na posição-sujeito linguista se contrapõe ao pensamento dos estudiosos da língua de sua época, fazendo um movimento de contra-identificação dentro da FD de que faz parte. Viria a se filiar e a se identificar mais com a Linguística do século XX. Essa tomada de posição permite a alguns estudiosos do autor considerá-lo como um sujeito com ideias adiantadas para seu tempo, um antecipador, um precursor. Para Wagner (1981, p.88), a atitude científica que Bello assumia diante do objeto de reflexão e a sua preocupação pelo ensino "[...] hicieron de él un gran linguista y no sólo un gran gramático." ${ }^{16}$.

\section{CONSIDERAÇÕES FINAIS}

Após identificar possíveis tomadas de posição-sujeito, que se inscrevem no Prólogo da Gramática de la lengua castellana destinada al uso de los americanos (1847), de Andrés Bello, podemos afirmar que o sujeito é dispersão, é heterogêneo. Ele se desdobra e se fragmenta a partir da sua constituição na/pela linguagem e da sua ilusão subjetiva.

O sujeito falante de castelhano é silenciado para que outro possa surgir - o gramático. Na verdade, quando Bello assume o papel de produzir conhecimento, ele toma uma posição, que é de sujeito-gramático. Para que esta predomine nesse discurso, é preciso que aquela se silencie porque não atende à norma, não produz o discurso que deve conter o prefácio e o corpo da gramática. Mas vimos que ela não se cala completamente (Recorte 1). Quando volta, identifica-se com os sujeitos falantes educados.

A posição-sujeito gramático em um livro chamado gramática predomina, mas, esse efeito de unidade subjetiva é uma ilusão. Desliza para outras posições-sujeito, a de professor e a de linguista, além daquela de que não se livra, a de falante da língua. Bello, na posiçãosujeito gramático, apresenta-se dividido, na medida em que se coloca como alguém que produz conhecimento afim ao que já vem sendo feito (RAE, gramáticos anteriores, apoio literário, unidade da língua, bem falar, uso da gente educada) e como alguém que se contra-identifica ao trazer inovações (ideias da linguística saussuriana, usos dos americanos educados, destinatário explícito no título, gramática continental). Apesar de inovar, provocando tensões, não chega a romper com a FD de que faz parte.

\footnotetext{
${ }^{15}$ Uma língua é um corpo vivente: sua vitalidade não consiste na constante identidade dos elementos, mas sim na regular uniformidade das funções que estes exercem e de que procedem a forma e a índole que distinguem do todo (tradução nossa).

${ }^{16}$ Fizeram dele um grande linguista e não somente um grande gramático. (tradução nossa).
} 


\section{REFERÊNCIAS}

AUROUX, S. A revolução tecnológica da gramatização. Tradução de Eni Puccinelli Orlandi. 3. ed. Campinas/SP: Editora da Unicamp, 2014.

BARROS, L. G.; DINIZ, A. G. (org.). Español: nuevos aportes y materiales. Nelool/DLLE/CCE - Florianópolis; [s.n], 2003.

BENVENISTE, E. Estrutura das relações de pessoa no verbo. (1946) In: Problemas de linguística geral I. Tradução de Maria da Glória Novak; Maria Luisa Neri. 4. ed. São Paulo: Pontes, 1995. p. 247-259.

BENVENISTE, E. A natureza dos pronomes (1956) In: Problemas de linguística geral I. Tradução de Maria da Glória Novak; Maria Luisa Neri. 4. ed. São Paulo: Pontes, 1995. p. 277-283.

BENVENISTE, E. Da subjetividade na linguagem. (1958) In: Problemas de linguística geral I. Tradução de Maria da Glória Novak; Maria Luisa Neri. 4. ed. São Paulo: Pontes, 1995. p. 284-293.

BENVENISTE, E. A linguagem e a experiência humana. (1965) In: Problemas de linguística geral II. Tradução de Eduardo Guimarães et al. São Paulo: Pontes, 1989. p. 68-80.

BENVENISTE, E. O aparelho formal da enunciação. (1970) In: Problemas de linguística geral II. Tradução de Eduardo Guimarães et al. São Paulo: Pontes, 1989. p. 81-92.

BRAIT, B. Enunciação e subjetividade. Revista Letras, Santa Maria, n. 33, p. 37-50, 2006.

GUIMARÃES, E. História, sujeito, enunciação. Cadernos de estudos linguísticos, Campinas, v. 35, p. 109-116, 1998. Disponível em: https://periodicos.sbu.unicamp.br/ojs/index.php/cel/article/view/8637132/4854. Acesso em: 04 maio 2018.

GUIMARÃES, E. Semântica do acontecimento. 4 ed. Campinas/SP: Pontes, 2017.

INDURSKY, F. Unicidade, desdobramento, fragmentação: a trajetória da noção de sujeito em Análise do Discurso. In: MitTMAnN, S.; GRIGOLETTO, E.; CAZARIN, E. (org.). Práticas discursivas e identitárias. Sujeito \& Língua. Coleção Ensaios. n. 22. Porto Alegre: Nova Prova, PPG-Letras/UFRGS, 2008. p. 9-93.

JAKSIC, I. A. Andrés Bello: la pasión por el orden. Estudio Crítico. Santiago de Chile: Editorial Universitaria, 2001.

ORLANDI, E. Língua e conhecimento linguístico: para uma história das ideias no Brasil. São Paulo: Cortez, 2002.

ORLANDI, E. Análise de discurso: Princípios e procedimentos. 12. ed. Campinas, SP: Pontes, 2015. 
ORLANDI, E. A análise de discurso em suas diferentes tradições intelectuais: o Brasil. In: SEMINÁRIO DE ESTUDOS EM ANÁliSE DO DISCURSO, 1, 2003, Porto Alegre. Anais... Porto Alegre: UFRGS, 2003. Disponível em: http://www.analisedodiscurso.ufrgs.br/anaisdosead/sead1.html. Acesso em: 04 maio 2018.

PÊCHEUX, M. Semântica e discurso: uma crítica à afirmação do óbvio. Tradução de Eni Puccinelli Orlandi et al. 5. ed. Campinas: Unicamp, 2014.

PÊCHEUX, M. A análise do de discurso: três épocas (1983). In: GADET, F. e HAK, T. Por uma análise automática do discurso: uma introdução à obra de Michel Pêcheux. Tradução de Bethania Mariani et al. 3. ed. Campinas/SP: Editora da Unicamp, 1997. p. 311 319.

PETRI, V. Algumas reflexões sobre o sujeito nos estudos da linguagem. Revista Línguas e instrumentos Linguísticos, Campinas, n. $13 / 14$, p. 65-74, 2004.

REAL ACADEMIA ESPAÑOLA. Diccionario de la lengua española. 22. Ed. Tomo II. Madrid: Espasa-Calpe, 2001.

SAUSSURE, F. de. Curso de linguística geral. Tradução de Antônio Chelini, José Paulo Paes, Isidoro Blikstein. 28.ed. São Paulo: Cultrix, 2012.

SURDI, M. I. A produção do saber sobre a língua nas gramáticas de Rocha Lima: o (não) lugar da significação. $2017.188 \mathrm{f}$. Tese (Doutorado em Letras). Universidade Federal de Santa Maria, Santa Maria, 2017.

WAGNER, C. La gramática de Andrés Bello. Revista Documentos lingüísticos y literarios, Valdivia, n. 7, p. 77-88, 1981. Disponível em: www.humanidades.uach.cl/documentos_linguisticos/document.php?id=238. Acesso em: 27 abr. 2018.

\section{OBRAS CONSULTADAS DE ANDRÉS BELLO}

BELLO, A. Gramática de la lengua castellana destinada al uso de los americanos. Santiago de Chile: Imprenta del progreso, 1847. Disponível em: Biblioteca Nacional Digital do Chile http://www.memoriachilena.cl/archivos2/pdfs/MC0014882.pdf Acesso em: 23 mar. 2018.

BELLO, A. Gramática de la lengua castellana. 1847. Madrid: EDAF, 2004.

BELLO, A. Discurso pronunciado en la instalación de la Universidad de Chile el día 17 de septiembre de 1843. p. 140-173. Disponível em: http://www.uchile.cl/portal/presentacion/historia/rectores-de-la-u-de-chile/4685/andres-bello-lopez-1843-1865. Acesso em: 23 mar. 2018.

BELLO, A. Obras completas de Andrés Bello. Poesias. V. III. Santiago de Chile: Impresso por Pedro G. Ramírez, 1883. Disponível em: Biblioteca Nacional Digital do Chile http://www.memoriachilena.cl/archivos2/pdfs/MC0064753.pdf. Acesso em: 23 mar. 2018.

\section{()(1) $\odot$}

